the preservation of amenities in country and town and the education of public opinion on these matters. This comprehensive report gives a clear impression of the many activities which engage the attention of the Council. The policy of the Council, which is discussed at some length, is based on the view that the development of agricultural resources, and the improvement of the social environment of the rural population, provide the best means of realizing the aims of the Council. National and regional planning of the land in the interest of the community is supported ; genuine rural industries are to be encouraged, while rural housing and services should be improved. Other sections are devoted to the location of industry and the provision of new towns, road construction, the provision of National Parks and open spaces, afforestation, prohibition of outdoor advertisements in certain localities, and the release of areas from military occupation. In many of these and other matters, the Council for the Preservation of Rural England works in close co-operation with other bodieg for example, the National Trust.

\section{Training Grants for Engineers}

THe Minjstrp of Labour and National Service is now awardifg grap under the Further Education and Trping sche to assist young engineers who haye bdu d Whilitary service to complete their pr f t pal trainfog in industry. University graduates in fing ineering find others who have qualified as graduates of the Institutions of Civil, Mechanical or Electrical Engineers are entitled to apply for grants. The awards are intended to supplement the payments which employers normally make to engineering graduates. A plan of training must be drawn up by the employer and approved by the Ministry before a grant will be made. Three types of course are contemplated, lasting twenty-four, twelve and six months respectively. The longest course is intended for those who have had no previous industrial experience and only limited technical experience in the Services. The Institution of Electrical Engineers announces that young electrical engineers will be advised to take a twelve-months course if they have had little or no industrial training, but have served eighteen months or more on suitable workshop duties in technical units, or have had 12-18 months previous industrial training and only limited technical experience on military service. Those with more than nine months previous industrial training and more than eighteen months technical experience in the Services will generally be regarded as having completed their training, but some may be advised to take the six-months course. Further particulars may be obtained from the Regional Appointments Officers of the Ministry of Labour and National Service. ran

\section{Catalogue of Scjentific Films in Britain}

A CATaLda compiled by the Scientific Film Associption 1.5 ts alphabetically 595 films of general scientrhungrest at present available in Great Buppif, rangthg from films of technique and process to 1 as relating science to society (London: Associa ign of Special Libraries and Information Bureaux. 5s.) Most films entirely of use for juvenile teaching have been excluded, but some films on cooking and related topies, and selected films on international relations, national cultures, ways of life and tradition have been included to give that social background against which all human activities must be assessed and studied. Of the films listed, 266 have been appraised and graded by special committees, and it is the intention of the Association to supply synopses, appraisals and gradings for every film and to keep the lists up to date in this respect. The graded films are marked recommended, suitable or unsuitable in three categories : for general audiences and audiences of mixed scientific workers; for more specialized audiences with a knowledge of the subject-matter of the film ; and for adult teaching or training purposes. Silent films are indicated by printing the title in italic capitals, and sound films with silent versions by an asterisk. Films of which the distribution is restricted for any reason are also marked, and sponsor and production agency, where traced, are indicated. The name of the distributor is usually abbreviated and followed by a catalogue reference for use in ordering. A list of film distributors with these abbreviations is included, and there is a classified subject index.

\section{Association of Scientific Workers : Social Sciences Committeg \\ A MEETry to inaugurate a National Social Sciences Committof of the Association of Scientific Workers will be/held in Gas Industries House, 1 Grosvenor Place London, S.W.1, on December 14. The meeting wily be held under the chairmanship of Mr. J. R. M.} Bhumwell. Prof. S. Zuckerman will speak on the outlook for the social sciences, Dr. G. Wagner will report on the work of the Social Sciences Cormmittee, Mr. D. Chapman will diseuss future work for social scientists in the Association of Scientific Workers, and Mr. R. Innes will discuss the constitution of a National Committee for Social Scientists. Further information can be obtained from the Honorary Secretary, Social Sciences Committee, Association of Scientific Workers, 15 Half Moon Street, Piccadilly, London, W.1.

\section{Announcements}

Sir Aexander Fleming and Sir Howard Florey have been/awarded the Gold Medals in Therapeuties of the Syciety of Apothecaries of London, in recognition of their discovery and work on penicillin.

THE title of professor emeritus in the University of Durblam has been conferred upon Prof. J. W. Heslop Harrison, formerly professor of botany, and Commander C. J. Hawkes, formerly professor of enfineering, both at King's College, Newcastle-uponTyne.

RECENT appointments to the staff of the University of Leed/ include the following: Dr. H. J. Rogers, to be Xuffield Research Fellow in oral biology; Dr. A. B. Moggy, to be Brotherton Research Lecturer in phrsical chemistry in the Department of Textile Industries ; Dr. R. N. Tattersall, to be lecturer (fulltime) in medicine.

Dr. A. C. Barton-Wright has been appointed microfologist to Whitbread and Co., Ltd., and has takg up his duties in the laboratories at Chiswell Street, London, E.C.1.

REFERRING to the notes under the title "Abnormal Solar/Radiation on 75 Megacycles" in Nature of Octpoer 12, p. 511, Dr. S. E. Williams states that the phrase (par. 2, line 3) "visual changes on the sun's disk as recorded on spectrohelioscope observations ..." should read, "visual changes on the sun, namely, the appearance of an eruptive prominence recorded in the spectrohelioseope observations ..." 